Int. J. Electrochem. Sci., 11 (2016) $4389-4398$

International Journal of

ELECTROCHEMICAL

SCIENCE

www.electrochemsci.org

\title{
A Facile Hydrothermal Synthesis of Ultrasmall Sn Nanoparticles in Carbon Matrices as Anode for Lithium Ion Battery
}

Jie $Q u^{1,2}$, YonganYang $^{2, *}$, ZhihuiChen $^{2}$, YurongRen $^{1}$, JianningDing $^{1, *}$, NingyiYuan $^{1}$

${ }^{1}$ School of Materials Science and Engineering, Jiangsu Collaborative Innovation Center of Photovoltaic Science and Engineering and Jiangsu Province Cultivation base for State Key Laboratory of Photovoltaic Science and Technology, Changzhou University, Changzhou 213164, P. R. China

${ }^{2}$ Department of Chemistry and Geochemistry, Colorado School of Mines, 1012 14th Street, Golden, CO, 80401, U.S.A

*E-mail: dingjn@cczu.edu.cn, Yongan@mines.edu

doi: $10.20964 / 2016.06 .12$

Received: 29 February 2016 / Accepted: 23 March 2016 / Published: 4 May 2016

Ultrasmall sub-5nm nanoparticles in carbon matrices are synthesized by a facile hydrothermal route. The morphology and structure of the prepared samples were characterized by transmission electron microscopy (TEM) and X-ray diffraction (XRD). The electrochemical performances were evaluated by galvanostatic cycling and cyclic voltammetry. It is found that among the three nanocomposites $\mathrm{Sn} / \mathrm{C}-3$ with $\mathrm{Sn}$ nanoparticles content of $20.9 \mathrm{wt} \%$ shows the best rate performance and the highest discharge capacity. At the current density of $200 \mathrm{~mA} \mathrm{~g}^{-1}$, it shows a high dicharge capacity of $851.8 \mathrm{mAh} \mathrm{g}^{-1}$. Even when the current density is increased to 5000 $\mathrm{mA} \mathrm{g}^{-1}$, a high discharge capacity of $168.1 \mathrm{mAh} \mathrm{g}^{-1}$ can still be obtained. This result indicates a potential suitability of fabricating $\mathrm{Sn} / \mathrm{C}$ electrode with high electrochemical performance.

Keywords: ultrasmall Sn; carbon; hydrothermal synthesis; lithum-ion battery

\section{FULL TEXT}

(C) 2016 The Authors. Published by ESG (www.electrochemsci.org). This article is an open access article distributed under the terms and conditions of the Creative Commons Attribution license (http://creativecommons.org/licenses/by/4.0/). 